OPEN ACCESS

Approved by:

Frontiers Editorial Office,

Frontiers Media SA, Switzerland

${ }^{*}$ Correspondence:

Wanxing Jiang

wanxing_jiang@163.com

Specialty section:

This article was submitted to

Organizational Psychology,

a section of the journal

Frontiers in Psychology

Received: 21 August 2019

Accepted: 23 August 2019

Published: 10 September 2019

Citation:

Chen S, Jiang W, Zhang G and Chu F

(2019) Corrigendum: Spiritual

Leadership on Proactive Workplace

Behavior: The Role of Organizational

Identification and Psychological

Safety. Front. Psychol. 10:2056.

doi: 10.3389/fpsyg.2019.02056

\section{Corrigendum: Spiritual Leadership on Proactive Workplace Behavior: The Role of Organizational Identification and Psychological Safety}

\author{
Silu Chen ${ }^{1}$, Wanxing Jiang ${ }^{2 *}$, Guanglei Zhang ${ }^{3}$ and Fulei Chu ${ }^{4}$ \\ ${ }^{1}$ School of Economics and Business Administration, Central China Normal University, Wuhan, China, ${ }^{2}$ School of Business \\ Administration, Shanghai Lixin University of Accounting and Finance, Shanghai, China, ${ }^{3}$ School of Management, Wuhan \\ University of Technology, Wuhan, China, ${ }^{4}$ College of Business Administration, Capital University of Economics and Business, \\ Beijing, China
}

Keywords: spiritual leadership, proactivity, organizational identification, psychological safety, intrinsic motivation, self-determination theory

\section{A Corrigendum on}

Spiritual Leadership on Proactive Workplace Behavior: The Role of Organizational Identification and Psychological Safety

by Chen, S., Jiang, W., Zhang, G., and Chu, F. (2019). Front. Psychol. 10:1206. doi: 10.3389/fpsyg.2019.01206

In the published article, there was an error in affiliation 2. Instead of "School of Business Administration, Shanghai Linxin University of Accounting and Finance, Shanghai," it should be "School of Business Administration, Shanghai Lixin University of Accounting and Finance, Shanghai, China."

Additionally, in the original article, there was an error. The software used was incorrectly provided as "AOMS20.0" instead of "AMOS20.0".

A correction has been made to the section Analysis and Results, subsection Measurement Model:

"Using the AMOS20.0 software, confirmatory factor analysis was used to test the goodness of fit of the measurement model."

The authors apologize for this error and state that this does not change the scientific conclusions of the article in any way. The original article has been updated.

Copyright $\odot 2019$ Chen, Jiang, Zhang and Chu. This is an open-access article distributed under the terms of the Creative Commons Attribution License (CC BY). The use, distribution or reproduction in other forums is permitted, provided the original author(s) and the copyright owner(s) are credited and that the original publication in this journal is cited, in accordance with accepted academic practice. No use, distribution or reproduction is permitted which does not comply with these terms. 